\title{
Radiofrequency Volumetric Thermal Ablation of Fibroids and Laparoscopic Myomectomy: Long-Term Follow-up From a Randomized Trial
}

\author{
Radiofrequenz-volumetrische Thermoablation von Myomen und Laparo- \\ skopische Myomektomie: Langzeit-Follow-up einer randomisierten Studie
}

Authors

Affiliations
M. Hahn ${ }^{1}$, S. Brucker ${ }^{1}$, D. Kraemer ${ }^{1}$, M. Wallwiener ${ }^{2}$, F.-A. $\operatorname{Taran}^{1}$, C. W. Wallwiener ${ }^{1 *}$, B. Krämer ${ }^{1 *}$

${ }^{1}$ Department of Obstetrics and Gynecology, University of Tübingen, Tübingen

${ }^{2}$ Department of Obstetrics and Gynecology, University of Heidelberg, Heidelberg

\author{
Key words \\ - radiofrequency volumetric \\ thermal ablation \\ - laparoscopic myomectomy \\ - fibroids \\ - laparoscopic ultrasound \\ - Acessa \\ Schlüsselwörter \\ - Radiofrequenz-volu- \\ metrische Thermoablation \\ - laparoskopische \\ Myomektomie \\ - Myome \\ - laparoskopischer Ultraschall \\ - Acessa
}

\section{Abstract \\ $\nabla$}

Aims: Laparoscopic myomectomy (LM) has been the gold standard treatment for uterine fibroids in women desiring uterine conservation. To evaluate a new fibroid treatment modality - radiofrequency volumetric thermal ablation (RFVTA) we compare 12-month results in women who had symptomatic uterine fibroids and who were randomized to laparoscopic ultrasound-guided RFVTA or LM.

Materials and Methods: Our study is a $1: 1$ parallel, randomized, prospective, single-center, longitudinal, comparative analysis of RFVTA to LM for fibroid treatment in women $\geq 18$ years of age who desired uterine conservation. Fifty women were randomized intraoperatively to RFVTA $(n=25)$ or to LM $(n=25)$ after laparoscopic ultrasound mapping of the uterus.

Results: Post surgery, ablation and myomectomy subjects took pain medications for 4 days (range: 1-46) and 7 days (range: 1-83 days) respectively $(\mathrm{p}=0.60)$. Ablation and myomectomy subjects missed 10.0 workdays (range: 2-86 days) and 17.0 workdays (range: $7-30$ days) $(\mathrm{p}=0.28)$, resumed normal activities in 20.5 days (range: 5103 days) versus 28.0 days (range: 10-42 days) $(\mathrm{p}=0.86)$ respectively. Mean symptom severity scores decreased (improved) by -7.8 for the ablation subjects and by -17.9 for the myomectomy subjects $(p=0.16)$. Health-related quality of life improved (increased) by 7.5 and 13.1, respectively, for the two groups $(p=0.46)$. Two myomectomy subjects had pregnancies that ended in a Cesarean delivery and a vaginal delivery of healthy infants. Two pregnancies in the RFVTA group ended in full-term vaginal deliveries of healthy infants.

Conclusions: Early postoperative recovery and twelve-month results attest to similar clinical benefits from RFVTA and LM.

* Joint senior author.

\section{Zusammenfassung \\ $\nabla$}

Zielsetzung: Die laparoskopische Enukleation von Myomen (LM) war bislang der Goldstandard bei Frauen mit Wunsch nach Uteruserhalt. Wir evaluieren die ultraschallgesteuerte thermale volumetrische Radiofrequenzablation (RFVTA) als eine neue Therapieoption: die 12-Monats-Ergebnisse von Patientinnen, die aufgrund symptomatischer Uterusmyome in die Therapiearme RFVTA oder LM randomisiert wurden, werden verglichen.

Material und Methoden: Es handelt sich um eine 1:1 parallele, longitudinale, randomisiert prospektive Single-Center-Vergleichsanalyse zwischen RFVTA und LM bei Frauen $\geq 18$ Jahren mit Wunsch nach Uteruserhalt. Nach laparoskopisch gesteuertem Ultraschall-Mapping des Uterus wurden insgesamt 50 Frauen intraoperativ in die beiden Arme RFVTA ( $n=25)$ oder LM $(n=25)$ randomisiert.

Ergebnisse: Nach Ablation und Myomektomie nahmen die Patientinnen für 4 (1-46d) bzw. 7 Tage (1-83 d) Schmerzmittel ein ( $p=0,60)$, fehlten $10(2-86 \mathrm{~d})$ bzw. 17 Arbeitstage (7-30 d) $(p=0,28)$ und kehrten nach 20,5 (5-103d) vs. 28,0 Tagen $(10-42 \mathrm{~d})(\mathrm{p}=0,86)$ wieder $z u$ ihren normalen Aktivitäten zurück. Im Mittel sank der Schweregrad der Symptome um -7,8 (RFVTA) und um $-17,9(\mathrm{LM})(\mathrm{p}=0,16)$. Die gesundheitsbezogene Lebensqualität verbesserte sich um 7,5 bzw 13,1 ( $p=0,46)$. Zwei Schwangerschaften traten nach Myomektomie ein und resultierten in einer Sectio und einer vaginalen Entbindung mit unauffälligen Kindern. Zwei Schwangerschaften im RFVTA-Arm führten zu vaginalen Spontanpartus ebenfalls unauffälliger Neugeborener.

Conclusio: Die rasche postoperative Erholungsphase und die 12-Monats-Ergebnisse lassen auf einen ähnlichen klinischen Nutzen der neuen RFVTA-Methode im Vergleich zur LM schließen. 


\section{Précis}

$\nabla$

Twelve-month qualitative results indicate similar efficacy, quality of life, and safety for both laparoscopic ultrasound-guided radiofrequency volumetric thermal ablation of fibroids and laparoscopic myomectomy.

\section{Introduction}

$\nabla$

Hysterectomy for symptomatic fibroid treatment is prevalent in parts of Europe and in the United States [1]. However, European and U.S. patients are increasingly seeking uterine-sparing therapy and fertility conservation [2]. Minimally invasive options such as ultrasound-guided laparoscopic myomectomy, uterine artery embolization, and magnetic resonance-guided focused ultrasound - are becoming popular among patients and their gynecologists [3]. Laparoscopic myomectomy (LM) has long been considered the gold standard treatment of symptomatic uterine fibroids in women desiring uterine conservation and fertility [46]. Advantages of LM over abdominal myomectomy include reduced blood loss, decreased postoperative pain, shorter hospital stay, and more rapid recovery [7]. However, the technical challenges of multilayer laparoscopic suturing require skill and experience, as well as extirpation of any deep intramural fibroids or fibroids located near the fallopian tubes with consequent uterotomy and myometrial scars.

A newer minimally invasive, outpatient, uterine-sparing approach to fibroid treatment has been described in the literature: laparoscopic radiofrequency volumetric thermal ablation (RFVTA, the Acessa ${ }^{\mathrm{TM}}$ Procedure, Halt Medical, Inc., Brentwood, California USA) [8-10]. Previously reported 3-month results from a large, multicenter trial of RFVTA were predictive of near- and long-term clinical outcomes [9]. Brucker et al. recently reported mean times to discharge from the hospital following RFVTA and LM (ClinicalTrials.gov Identifier: NCT01750008) [11]. Their study confirmed significantly shorter mean hospitalization for subjects undergoing RFVTA compared to those undergoing LM.

The purpose of this follow-up to Brucker et al.'s earlier report [11] is to analyze, compare and describe that study's 3-, 6-, and 12month outcomes in terms of pain medication use, recovery from surgery, and subjects' subjective responses to validated questionnaires.

\section{Materials and Methods}

\section{Study design}

This 1:1 parallel randomized, prospective, single-center, longitudinal, comparative study of clinical and safety outcomes after laparoscopic ultrasound-guided RFVTA and ultrasound-guided laparoscopic myomectomy was designed for women $\geq 18$ years of age with uterine sizes of $<16$ gestational weeks, who had symptomatic fibroids ( $<10 \mathrm{~cm}$ in any diameter) detected by transvaginal ultrasound, and who desired uterine conservation and preservation of fertility [11]. Exclusion criteria applied to those women who: were contraindicated for laparoscopic surgery and/or general surgery, were known to have significant intra-abdominal adhesions, had an implanted intrauterine or fallopian tube contraceptive device, had chronic pelvic pain not due to fibroids, had known or suspected endometriosis or adenomyosis, had active (or a history of) pelvic inflammatory disease, had a history of (or evidence of) gynecologic malignancy or premalignancy within the past 5 years, had a cervical myoma, or had one or more completely intracavitary submucous fibroids or only type $0 / 1$ submucous fibroids that are better treated via hysteroscopic methods [11].

Subjects were recruited from referral gynecologists beginning in mid-2012 in Germany, and study subjects were enrolled at the Women's Hospital at the University of Tübingen between November 1, 2012 and June 30, 2013. The University of Tübingen Local Ethics Committee approved the protocol. An independent third party (CenTrial GmbH, Tübingen, Germany) monitored the data and an independent biostatistics company (Innovative Analytics, Kalamazoo, Michigan USA) analyzed all monitored data. The 50 enrolled women were informed of the purpose of the study, study testing, expected duration of 60 months of followup, and potential risks and benefits of participation. They were treated at Tübingen University Women's Hospital in Tübingen, Germany.

\section{Intraoperative treatment randomization and operative technique}

Randomization occurred as an intraoperative step following contact laparoscopic ultrasound mapping of the uterus; the latter provided classification, size, and location of all fibroids within the uterus. Once each subject's fibroids were mapped and recorded on the treatment case report form, the surgeon, who up to this point was blinded as to which treatment method would be assigned - RFVTA or LM - drew an envelope containing the subject's treatment assignment ( $\bullet$ Fig. 1). The assignments were computer-generated in blocks of 6 or 4 by an independent biostatistics company (Innovative Analytics, Kalamazoo, Michigan USA).

Brucker et al. have described the treatment approaches in detail [11]. Briefly, subjects randomized to LM received the standard surgical procedure in the lithotomy position. Two-layer suturing was used, as a standard of care, only for deep intramural fibroids or for those without endometrial or serosal distortion ( $\bullet$ Fig. 2 a). Though not a protocol exclusion, surgeons performing LM chose not to excise small $(1.0-1.5-\mathrm{cm}$ diameter) deep intramural fibroids.

Subjects undergoing RFVTA first had 3-5 core tissue needle biopsies from their largest fibroid and the samples were sent to pathology for routine analysis. The tip of the Acessa handpiece (3.4 $\mathrm{mm}$ in diameter) was then inserted and advanced into the fibroid via the same tract as the biopsy needle. The needle electrodes were deployed depending on the size of the fibroid, the ablation was carried out, and the tract was coagulated upon handpiece tip removal, therein providing hemostasis ( $\bullet$ Fig. 2 b). For both LM and RFVTA, the port sites were closed per standard procedure. Subjects were followed via phone, mail, and/or an inperson interview at 3, 6, and 12 months post procedure.

\section{Outcome measures}

The primary outcome measure of the study (hospitalization time) has been reported in the literature [11]. In this longer term follow-up of the same study, we report on qualitative outcomes through one year post treatment: subjects' subjective responses to validated questionnaires (Uterine Fibroid Symptom and Quality-of-Life (UFS-QOL), EQ-5D, Overall Treatment Effect Survey (OTE), and menstrual impact (MIQ) questionnaires [12-15]), their use of pain medication, procedure-related complications, re-interventions for fibroid symptoms, and pregnancy outcomes. 


\section{Assessed for eligibility $(n=110)$}

Excluded $(n=54)$

- Not meeting inclusion criteria $(n=54)$

Intraoperative mapping $(\mathrm{n}=56)$

\begin{tabular}{|c|c|}
\hline & $\begin{array}{l}\text { Excluded }(\mathrm{n}=5) \\
1 \text { subject had a fibroid }>10 \mathrm{~cm} \text { and } \\
\text { an IUD in place; } \\
2 \text { subjects had many fibroids, and if } \\
\text { randomized to laparoscopic } \\
\text { myomectomy, would have had } \\
\text { a hysterectomy; } \\
1 \text { subject had no fibroids; } \\
1 \text { subject had only } 1 \text { large } \\
\text { pedunculated fibroid }\end{array}$ \\
\hline \multicolumn{2}{|c|}{ Randomized $(n=51)$} \\
\hline \multirow{2}{*}{$\begin{array}{l}\text { Allocated to RFVTA ( } n=26) \\
\text { Received allocated intervention and } \\
\text { followed through } 3 \text { months }(n=25) \\
\text { Did not receive allocated intervention } \\
(n=1), \text { procedure was terminated } \\
\text { because of an unrelated operating } \\
\text { room emergency }\end{array}$} & 7 \\
\hline & $\begin{array}{l}\text { Allocated to LM }(\mathrm{n}=25) \\
\text { Received allocated intervention and } \\
\text { followed through } 3 \text { months }(\mathrm{n}=25)\end{array}$ \\
\hline$\downarrow$ & $\downarrow$ \\
\hline $\begin{array}{l}\text { Analyzed at } 6 \text { months }(n=23) \\
\text { Excluded from analysis: } \\
\text { hysterectomy }(n=2)\end{array}$ & $\begin{array}{l}\text { Analyzed at } 6 \text { months }(n=23) \\
\text { Excluded from analysis: } \\
\text { missing data }(n=2)\end{array}$ \\
\hline$\nabla$ & $\downarrow$ \\
\hline $\begin{array}{l}\text { Analyzed at } 12 \text { months }(n=21) \\
\text { Excluded from analysis: } \\
\text { missing data }(n=1) \text {; }\end{array}$ & $\begin{array}{l}\text { Analyzed at } 12 \text { months }(n=22) \\
\text { Excluded from analysis: } \\
\text { missing data }(n=1)\end{array}$ \\
\hline
\end{tabular}

Fig. 1 Disposition of subjects throughout study. Flow of subjects through 12 months of follow-up (modified from Figure 1, reference [11]).

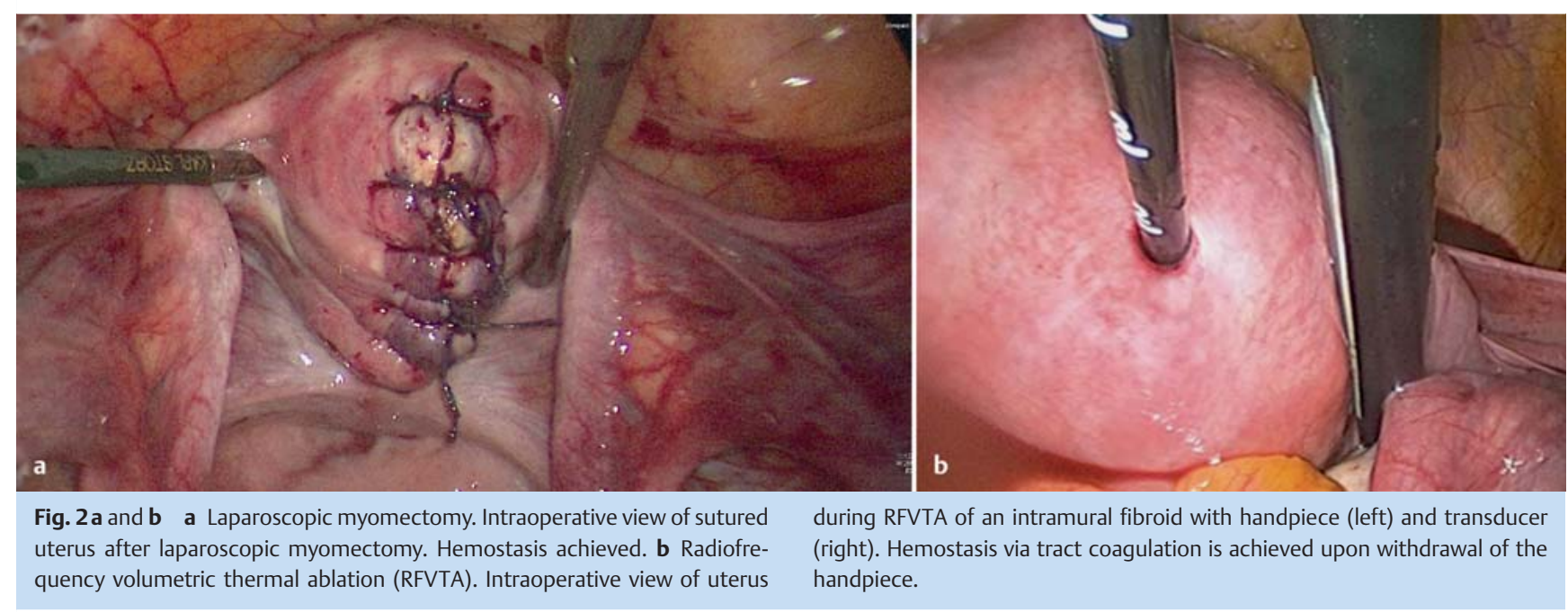


Table 1 Demographics of study participants and intraoperative myoma characteristics at baseline (modified from Table 2, reference [11]) ${ }^{\mathrm{a}, \mathrm{b}}$.

\begin{tabular}{|c|c|c|c|}
\hline \multirow[t]{2}{*}{ Variable } & \multicolumn{3}{|l|}{ Baseline } \\
\hline & RFVTA ( $n=25)$ & $\operatorname{LM}(n=25)$ & p-value \\
\hline Mean age, years (SD) & $40.0(7.8)$ & $34.4(6.1)$ & 0.006 \\
\hline Mean height, cm (SD) & $166.0(5.8)$ & $164.4(5.9)$ & 0.33 \\
\hline Mean weight, kg (SD) & $62.4(8.9)$ & $64.9(13.5)$ & 0.43 \\
\hline \multicolumn{4}{|l|}{ Race, $n(\%)$} \\
\hline - White/Caucasian & $25(100)$ & $25(100)$ & \\
\hline \multicolumn{4}{|l|}{ Intraoperative myoma characteristics } \\
\hline - Total fibroids, $\mathrm{n}$ & 72 & 61 & \\
\hline - Mean number of fibroids per subject (SD; median: range) & $2.9(2.6 ; 2: 1-9)$ & $2.4(1.6 ; 2: 1-6)$ & 0.99 \\
\hline - Submucosal, $\mathrm{N}(\%)$ & $0(0.0)$ & $2(3.3)$ & 0.17 \\
\hline - Transmural, N (\%) & $0(0.0)$ & $3(4.9)$ & 0.17 \\
\hline - Intramural, $\mathrm{N}(\%)$ & $33(45.8)$ & $26(42.6)$ & 0.45 \\
\hline - IMAE, N (\%) & $2(2.8)$ & $0(0.0)$ & 0.17 \\
\hline - Subserosal, N (\%) & $37(51.4)$ & $34(55.7)$ & 0.21 \\
\hline - Pedunculated subserosal, N (\%) & $0(0.0)$ & $2(3.3)$ & 0.17 \\
\hline
\end{tabular}

a RFVTA = radiofrequency volumetric thermal ablation; LM = laparoscopic myomectomy; SD = standard deviation; IMAE = intramural abutting the endometrium

b Intraoperative myoma characteristics were evaluated by laparoscopic ultrasound mapping of the uterus prior to treatment/excision.

c P-values based on t-test for age, height, and weight; p-values were based on Wilcoxon test for fibroids.

Table 2 Number and percentage of subjects reporting symptoms at baseline and at 12 months.

\begin{tabular}{|c|c|c|c|c|c|c|}
\hline \multirow[t]{2}{*}{ Symptom } & \multicolumn{3}{|l|}{ Baseline } & \multicolumn{3}{|l|}{12 months } \\
\hline & $\begin{array}{l}\text { RFVTA (n = 25) } \\
\text { n (\%) }\end{array}$ & $\begin{array}{l}\operatorname{LM}(n=25) \\
n(\%)\end{array}$ & p-value & $\begin{array}{l}\text { RFVTA }(n=21) \\
n(\%)\end{array}$ & $\begin{array}{l}\operatorname{LM}(n=22) \\
n(\%)\end{array}$ & p-value \\
\hline Heavy menstrual bleeding & $21(84.0)$ & $18(72.0)$ & $0.31^{\mathrm{a}}$ & $7(33.3)$ & $2(9.1)$ & $0.069^{\mathrm{b}}$ \\
\hline Increased abdominal girth & $7(28.0)$ & $5(20.0)$ & $0.51^{\mathrm{a}}$ & $3(14.3)$ & $1(4.5)$ & 0.34 \\
\hline Dyspareunia & $3(12.0)$ & $6(24.0)$ & 0.46 & $0(0.0)$ & $0(0.0)$ & \\
\hline Pelvic discomfort/pain & $10(40.0)$ & $11(44.0)$ & $0.77^{\mathrm{a}}$ & $1(4.8)$ & $2(9.1)$ & 1.00 \\
\hline Dysmenorrhea & $7(28.0)$ & $8(32.0)$ & $0.78^{a}$ & $2(9.5)$ & $2(9.1)$ & 1.00 \\
\hline Urinary frequency & $13(52.0)$ & $9(36.0)$ & $0.25^{\mathrm{a}}$ & $3(14.3)$ & $1(4.5)$ & 0.34 \\
\hline Urinary retention & $4(16.0)$ & $8(32.0)$ & $0.19^{\mathrm{a}}$ & $0(0.0)$ & $0(0.0)$ & \\
\hline Sleep disturbance & $0(0.0)$ & $1(4.0)$ & 1.00 & $0(0.0)$ & $0(0.0)$ & \\
\hline Uterine pain & $3(12.0)$ & $1(4.0)$ & 0.61 & $0(0.0)$ & $0(0.0)$ & \\
\hline Backache & $7(28.0)$ & $6(24.0)$ & $0.75^{\mathrm{a}}$ & $1(4.8)$ & $2(9.1)$ & 1.00 \\
\hline Localized pain & $5(20.0)$ & $5(20.0)$ & $1.00^{\mathrm{a}}$ & $0(0.0)$ & $1(4.5)$ & 1.00 \\
\hline Other & $0(0.0)$ & $1(4.0)$ & 1.00 & $2(9.5)$ & $0(0.0)$ & 0.23 \\
\hline
\end{tabular}

a P-value based on $\mathrm{X}^{2}$ test, otherwise based on Fisher's exact test.

b P-value is 0.088 based on logistic regression controlling for baseline heavy menstrual bleeding.

Sample size and statistical analyses

The determination of the sample size has been reported in detail [8]. In brief, the sample size required for comparison of RFVTA and LM was based on assumptions with regard to hospitalization time. The null hypothesis was that RFVTA is more than $10 \%$ worse than LM concerning hospital stay and the alternative hypothesis was that this is not the case. The sample size required to reject the null hypothesis with a power of 0.80 was 50 ( 25 in each surgical group).

Analyses were performed using SAS version 9.3 (SAS Institute, Cary, North Carolina, USA). Continuous variables for the analyses performed for this study were summarized using descriptive statistics, whereas categorical variables were summarized in terms of frequencies and percentages. The precision of selected questionnaire outcomes for each treatment group is presented using 95\% confidence intervals. Statistical tests comparing the two treatment groups were performed using the t-test, unless otherwise noted.

\section{Results}

\section{$\nabla$}

Demographics, fibroid dimensions,

and symptomatology

Demographic and baseline symptomatology summaries for subjects in each of the two treatment groups are presented in $\odot \mathrm{Ta}$ bles 1 and 2, respectively. Subjects in the RFVTA and LM groups were similar with regard to height and weight, although the RFVTA subjects were several years older $(p=0.006)$. At baseline, symptomatology was similar between the two groups $(\mathrm{p}=0.19$ to $1.00, X^{2}$ or Fisher's exact test).

The surgeons incorporated intraoperative laparoscopic ultrasound not only to detect the uterine fibroids, but to measure the sum of their major diameters. For those women in the ablation group, the mean sum at baseline was $7.7 \pm 4.2 \mathrm{~cm}$; for those women randomized to myomectomy, the mean sum was $6.6 \pm 3.2 \mathrm{~cm}$. For those fibroids that were present and measurable at 12 months in the 19 subjects in each group, the mean sum of 


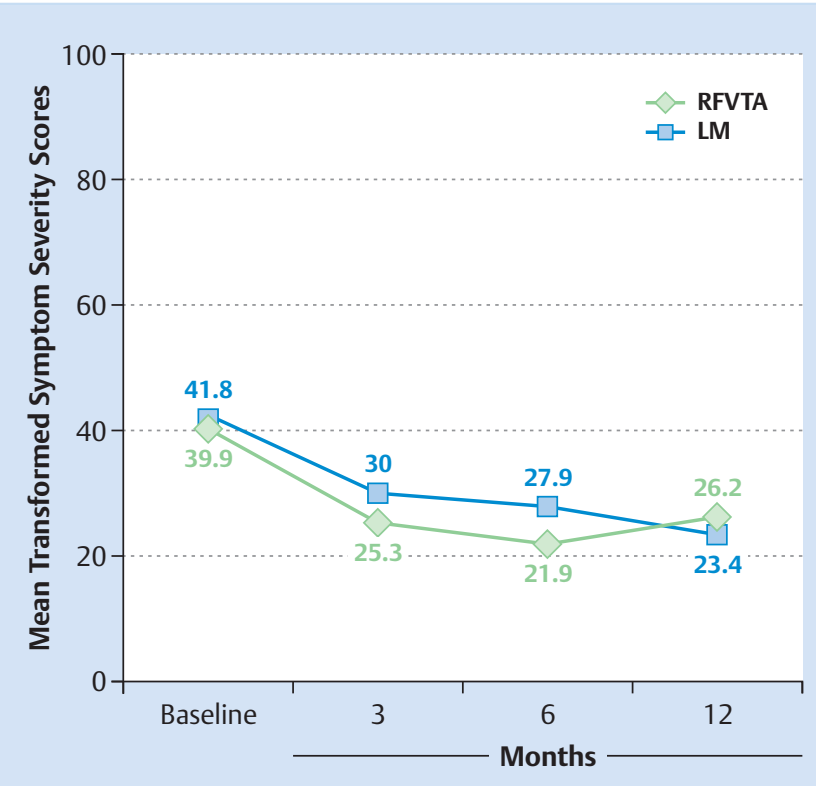

Fig. 3 Mean transformed uterine fibroid symptom severity scores. Symptom Severity scores for both radiofrequency volumetric thermal ablation (RFVTA) and laparoscopic myomectomy (LM) subjects. Note: The sample sizes at baseline, 3 months, 6 months, and 12 months are 25, 24, 23, and 18 for the RFVTA group; 25, 25, 22, and 20 for the LM group.

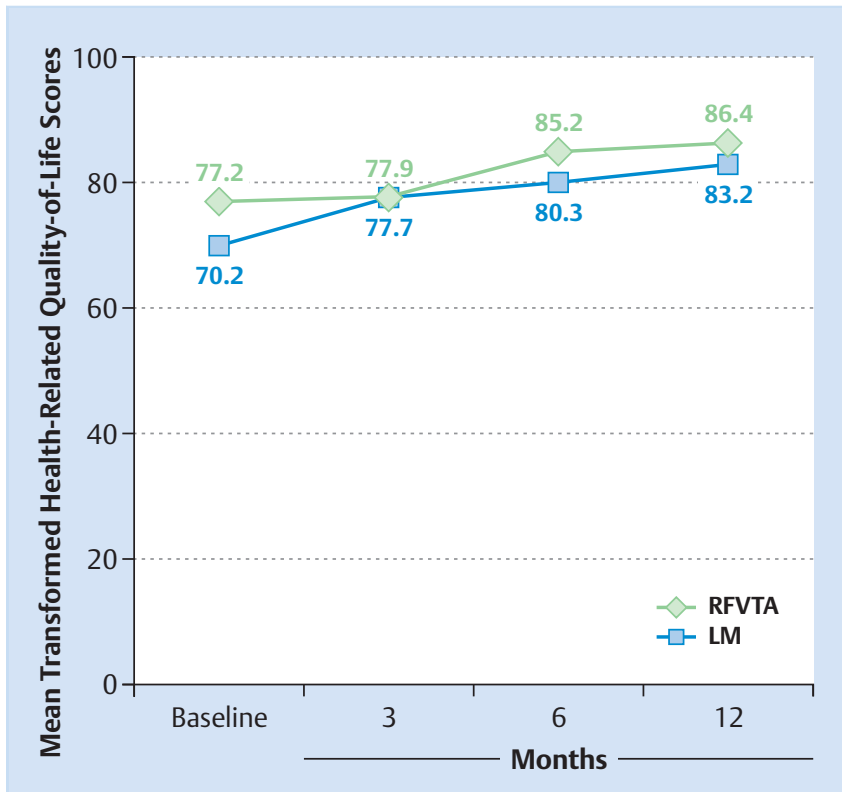

Fig. 4 Mean transformed uterine fibroid health-related quality-of-life scores. Health-Related Quality of Life scores for both RFVTA and LM subjects. Note: The sample sizes at baseline, 3 month, and 6 months are 25 , 24, 23, and 20 for the RFVTA group; 25, 24, 23, and 21 for the LM group.

2-86 days) including the procedure day. Of the 18 myomectomy subjects who worked outside the home, 17 returned to work and missed a median of 17.0 workdays (range, $7-30$ days) $(p=0.28)$.

\section{Uterine Fibroid Symptom Severity}

\section{and Quality-of-Life (UFS-QOL) outcomes}

Uterine Fibroid Symptom Severity and Health Related Quality-ofLife (HRQL) scores over time are presented in 0 Figs. 3 and 4 . The mean symptom severity score (the higher the score, the worse the severity) at baseline was 41.8 for the LM group and 39.9 for the RFVTA group, while the mean HRQL score (the lower the score, the worse the quality of life) was 70.2 for the myomectomy group and 77.2 for the ablation group.

For the 18 ablation subjects with both baseline and 12-month symptom severity data, mean transformed symptom severity scores decreased (improved) from baseline to 12 months by -7.8 to 26.2 , whereas the corresponding 20 myomectomy subjects achieved a reduction of -17.9 to 23.4 over the same period (mean difference of $10.1 \pm 21.6 ; 95 \% \mathrm{Cl}:-4.1,24.3 ; \mathrm{p}=0.16$ ).

HRQL increased (improved) for both groups over 12 months of follow-up, with mean increases of 7.5 to 86.4 and 13.1 to 83.2 for the ablation and myomectomy subjects, respectively, with both baseline and 12 month HRQL data (mean difference of $-5.6 \pm 24.1 ; 95 \% \mathrm{Cl}:-20.8,9.7, \mathrm{p}=0.46)$. The mean 12 -month HRQL subscale scores (describing patient-reported concern, activities, energy/mood, control, self-consciousness, and sexual function) were similar between both treatment groups ( $\bullet$ Fig. 5).

\section{Health state (EQ-5D) outcomes}

The mean health state (EQ-5D) scores (the lower the score, the worse the health state) at baseline through 12 months are presented in 0 Fig. 6. The mean EQ-5D score at baseline was 72.3 for the myomectomy subjects and 81.7 for the ablation subjects. Both groups reached their highest score at 6 months. Ablation 


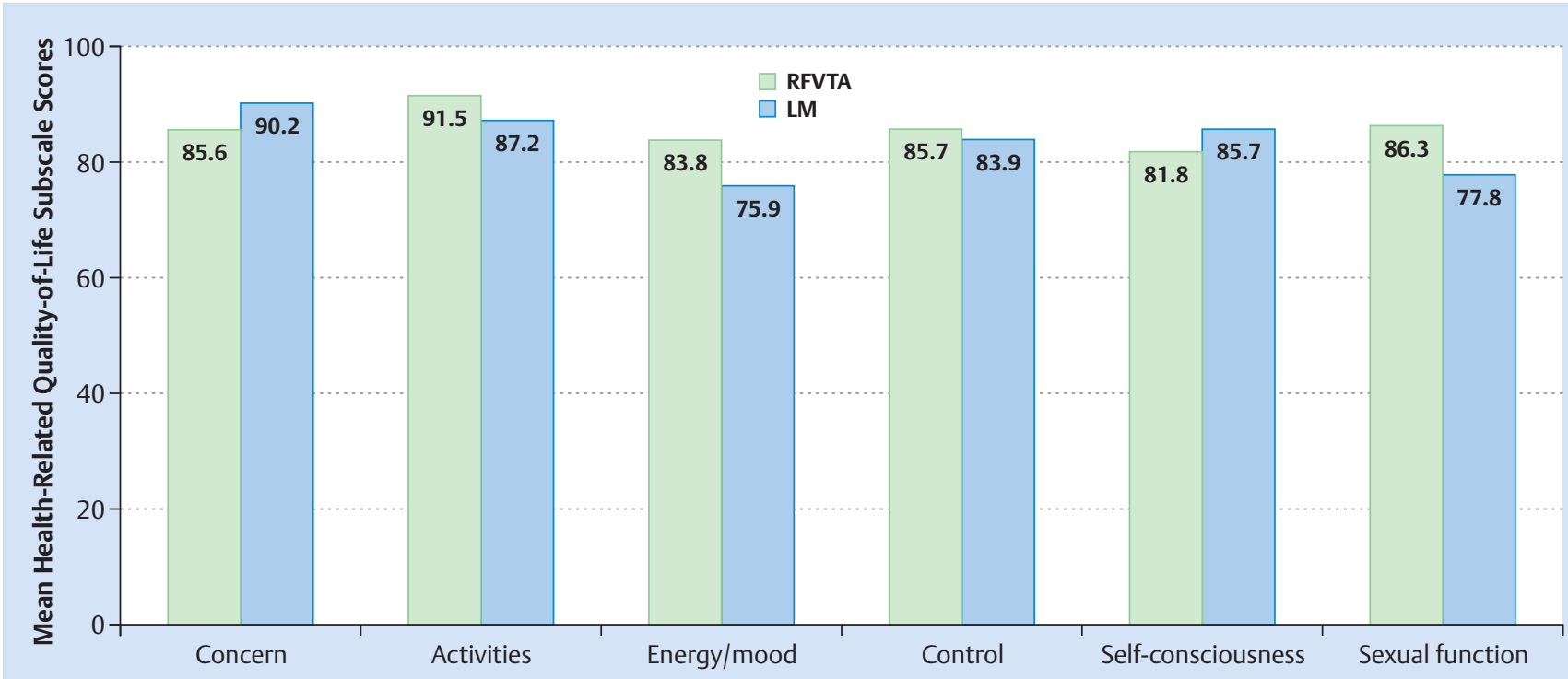

Fig. 5 Mean transformed health-related quality-of-life subscale scores. Health-related quality-of-life subscale scores at 12 months of follow-up for RFVTA and LM subjects.

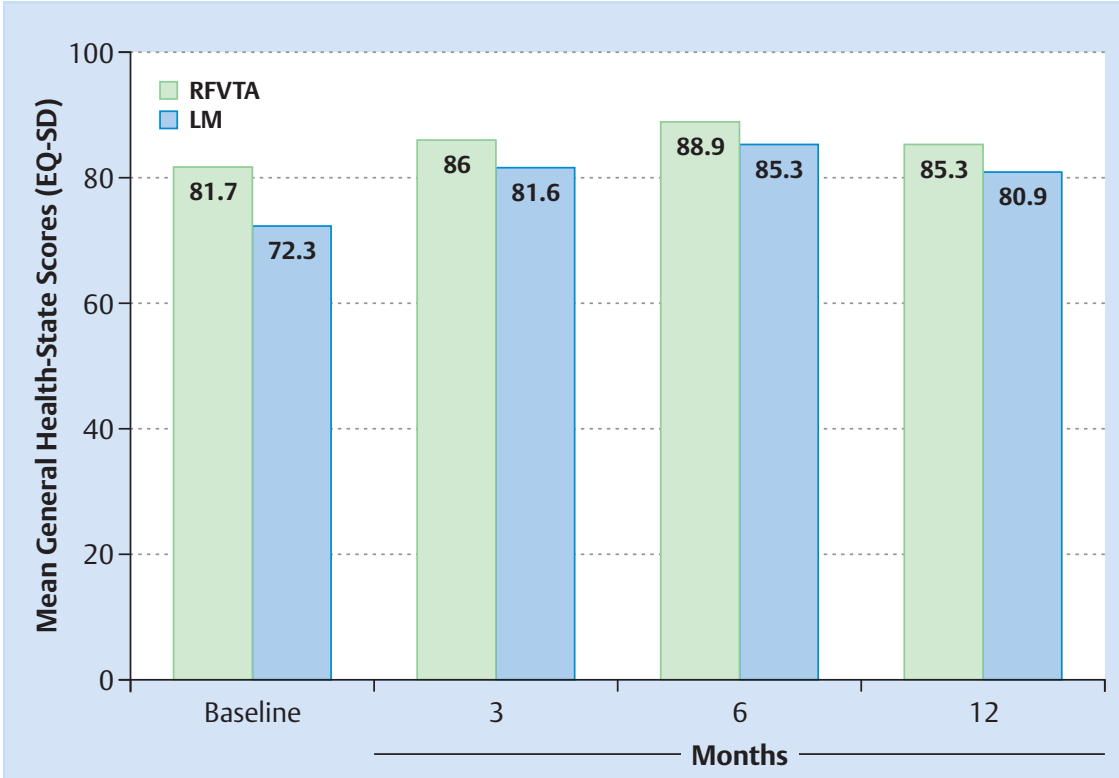

Fig. 6 Mean health state (EQ-5D) scores. Mean health state (EQ-5D) scores over time for both RFVTA and LM subjects.

subjects with both baseline and 12-month data achieved a mean change from baseline to 12 months of 2.0 , compared with a mean change of 8.9 for the myomectomy subjects. The mean difference in the increase in scores between the ablation and myomectomy treatment groups was $-6.8 \pm 18.8$ (95\% CI: $-18.4,4.7 ; \mathrm{p}=0.24)$.

\section{Menstrual Impact Questionnaire}

The Menstrual Impact Questionnaire (MIQ) was used to gauge subjects' perceptions of blood loss from the previous period. At 12 months follow-up, $94.4 \%$ of ablation respondents reported "better" or "about the same" compared to their previous period. At the same follow-up period, $84.3 \%$ of the LM subjects reported that their bleeding was "better" or "about the same" ( $p=0.12$, Wilcoxon test).

\section{Overall Treatment Effect (OTE)}

In terms of subject responses regarding overall treatment satisfaction at 12 months based on the Overall Treatment Effect (OTE) Survey, 42.9\% (9/21) of the ablation respondents reported being very satisfied with the treatment, $42.9 \%(n=9)$ were moderately satisfied, $9.5 \%(n=2)$ were somewhat satisfied, and $4.8 \%$ $(n=1)$ were moderately dissatisfied with the treatment due to the presence of hypermenorrhea at 4 weeks follow-up. Also at 12 months, 86.5\% ( $n=19)$ myomectomy subjects reported being very satisfied with the treatment, whereas $13.6 \%(n=3)$ reported being moderately satisfied ( $\mathrm{p}=0.004$, Wilcoxon test). No subject in either group reported being very dissatisfied with her treatment. 
In terms of responses to the question, "Would you recommend this treatment to a friend with the same health problem?" $33.3 \%$ of the ablation respondents reported that they would definitely recommend RFVTA, 61.9\% would probably recommend RFVTA, and $4.8 \%$ would probably not. In the myomectomy group, $54.5 \%$ would definitely recommend $\mathrm{LM}$, whereas $45.5 \%$ would probably recommend $\mathrm{LM}$ ( $\mathrm{p}=0.14$, Wilcoxon test).

In response to the question "How effective was the treatment in eliminating symptoms?" $23.8 \%$ of the ablation group found that the treatment was very effective, $57.1 \%$ found it moderately effective, $9.5 \%$ found it somewhat effective, $4.8 \%$ regarded it as somewhat ineffective, and $4.8 \%$ found it very ineffective. Of the myomectomy respondents, $45.5 \%$ found the treatment very effective, $31.8 \%$ found it to be moderately effective, and $22.7 \%$ found it to be somewhat effective ( $p=0.32$, Wilcoxon test).

\section{Procedure-related complications and re-interventions}

There was one serious complication that occurred during the early postoperative follow-up period in a subject who had undergone RFVTA and was experiencing hypermenorrhea. Dilation and curettage resulted in uterine perforation and subsequent hysterectomy. Another ablation subject underwent a preemptive hysterectomy after a biopsy revealed a fibroid of smooth muscle tumor of uncertain malignant potential (STUMP) [11]. Histopathologic analysis of the uterus and fibroids confirmed no malignancy. One myomectomy subject had a hematoma at the trocar site, which resolved without sequelae.

There was one elective surgical re-intervention in the ablation group. A 30-year-old subject presented with a single $6.3-\mathrm{cm}$ intramural fibroid at baseline, and the fibroid had decreased to $2.5 \mathrm{~cm}$ by 6 months. Though she reported to be asymptomatic at the 6-month visit, she desired pregnancy in the near future. Transvaginal ultrasound at 9 months showed an increase in the fibroid's diameter to $4 \mathrm{~cm}$; therefore, she sought myomectomy prior to attempting pregnancy.

\section{Pregnancy outcomes}

There were 5 pregnancies in 4 subjects within the first 9 months of follow-up: a myomectomy subject (GOP0) conceived; however, the fetus was anacephalic and was aborted. The same woman conceived again after excision of 5 fibroids measuring 0.7 to $2.0 \mathrm{~cm}$; she had a full-term pregnancy with Cesarean delivery (adhesions were noted) of a healthy male infant weighing $3310 \mathrm{~g}$ (Apgars 1 minute/5 minutes, 10/10). Another myomectomy patient (G1P0), who had a spontaneous abortion in 2012 before the trial began, conceived after excision of a $1.5-\mathrm{cm}$ intramural fibroid and a 0.9 subserosal fibroid. This pregnancy concluded with a spontaneous vaginal delivery at 39 weeks of a healthy female (Apgars 1 minute/5 minutes, 5/8) weighing $3280 \mathrm{~g}$. A third patient (G3P1), who was 31 years old, underwent RFVTA of a 5.7-cm intramural fibroid, conceived at 8.5 months post ablation, and vaginally delivered a healthy male infant at 40 weeks (Apgars 1 minute/5 minutes, 8/8; weight, 3880 g). Last, a 31 year-old GOP0 woman underwent RFVTA of a 3.3-cm intramural fibroid abutting the endometrium for heavy menstrual bleeding symptoms. There were no complications intra- or postoperatively, and the subject was free of fibroid symptoms by 3 months post ablation. She conceived 7 months post surgery and spontaneously delivered a healthy female baby (Apgars 1 minute/5 minutes, 10/10; weight, $3260 \mathrm{~g}$ ) at 39 weeks gestation. All 4 subjects will remain in the study.

\section{Discussion}

$\nabla$

Management of fibroid symptoms ranges from medical therapy to the most definitive approach, hysterectomy. Along this range of care, fibroid ablation and laparoscopic myomectomy offer uterine-conserving therapies that can be considered when medical treatment fails, is inappropriate, or is not well tolerated. This study provides the first description of 12-month outcomes in women with symptomatic fibroids who were randomized to laparoscopic myomectomy and to radiofrequency volumetric thermal ablation for treatment of their fibroid symptoms. Both treatment groups improved in terms of their reported symptom severity, health-related quality of life, and EQ-5D health state at 12 months. However, the differences in improvements between both groups were not statistically significant. The only significant difference detected between the two groups was in the degree of treatment satisfaction (very vs. moderately satisfied) favoring the myomectomy group.

The perception of blood loss from the previous period as measured by the MIQ indicated that RFVTA subjects had a more favorable perception, in contrast to the higher proportion of subjects in the RFVTA group who reported having heavy menstrual bleeding at 12 months. These somewhat contradictory results could have to do with the magnitude of the blood loss both at 12 months and at the preceding period for subjects in each group. The relationships between perception of blood loss and treatment, as well as between heavy menstrual bleeding and treatment, were not very strong. It is interesting to note that the location of the fibroids in both groups were almost entirely intramural and subserosal. Galen et al. reported on the decrease in menstrual bleeding associated with ablation of intramural fibroids and the importance of intramural fibroids in the evaluation of heavy menstrual bleeding [16].

We previously reported that subjects who underwent the ablative therapy experienced significantly improved perioperative outcomes in terms of shorter hospital stays and less blood loss [11]. We found that these women also needed pain medication for fewer days than did the myomectomy patients, and the ablation subjects missed fewer days from work and returned earlier to normal activities.

RFVTA of fibroids causes intracellular friction or heat, which results in necrosis of the target fibroid tissue with resultant shrinking and absorption by the surrounding myometrium. In Chudnoff et al., contrast-enhanced magnetic resonance imaging revealed that the total mean fibroid volume decreased by $45.1 \%$ at 12 months post ablation [8]. Because RFVTA does not require serosal and myometrial suturing, it can be used safely to treat fibroids smaller than $1 \mathrm{~cm}$ in diameter and has been used to ablate up to 29 fibroids in a single patient [8]. The ablation of small fibroids may preclude their growth with consequent symptoms. Day Baird et al. reported a prospective observational study of 36 women with fibroids, whose volumes were tracked every 3 months over one year [17]. They found that "much of the observed growth in fibroids $<5 \mathrm{~cm}$ in diameter appears to be associated with growth spurts. Treatments that could prevent spurts could limit the number of tumors that become large enough to cause symptoms." This finding supports treatment or ablation of fibroids as small as 0.5 to $1.0 \mathrm{~cm}$ that might cause future symptoms.

All subjects in both groups saw their ultrasound scans at 3 and 6 months. The increased expression of satisfaction with treatment by the LM subjects compared to the RFVTA subjects may have 
been due to a lack of understanding of the clinical significance of fibroid ablation by the ablation group. These women may have expected a great decrease in size or disappearance of their fibroids by 12 months as evidenced by ultrasound and may have correlated their perceptions at ultrasound with expected symptom improvement. The one elective surgical re-intervention in the RFVTA group was a myomectomy of a single intramural fibroid that measured $6.3 \mathrm{~cm}$ at baseline, decreased to $2.5 \mathrm{~cm}$ by 6 months, and - on transvaginal ultrasound at 9 months - appeared to increase to $4 \mathrm{~cm}$. The subject sought myomectomy prior to attempting pregnancy. Two hysterectomies were performed for reasons unrelated to fibroid symptoms. One was a preemptive treatment related to a STUMP fibroid, which was later confirmed to be nonmalignant [11]. The other was caused by the unknowingly aggressive treatment of hypermenorrhea via curettage (within a few weeks after the subject's RFVTA procedure) with corresponding perforation of the uterus.

All of the outcomes must be taken in the aggregate: most of the evaluations point toward similar benefits of improved efficacy and safety of RFVTA and LM. However, because of the local practice of tissue sampling of large fibroids and the relative unfamiliarity with RFVTA by local gynecologists, two women underwent hysterectomy - perhaps both of them unnecessarily.

The principal strength of the study was the computer-generated randomization of the subjects to either RFVTA or LM; randomized controlled trials are, by definition, rigorous. Despite randomization, there were study limitations and weaknesses, which included an unexpected age discrepancy between the groups. This discrepancy might potentially have biased the results in terms of subjects' perceptions of symptoms and their expectations of symptom relief. Differences in reported symptomatology (ه Table 2) may also correlate with the age of the study participants, but the small sizes of the study groups make it difficult to evaluate such a relationship; regardless, symptom differences were not statistically significant. Also, despite being randomized to one of the two laparoscopic treatments intraoperatively, patients were told postoperatively their assigned treatment. This knowledge may have impacted their responses to questionnaires. Last, data were missing for 2 RFVTA subjects and 3 LM subjects at 12 months. Given the small size of the groups, inclusion of additional responses from 2 and 3 more subjects could have made substantial differences in the reported outcomes.

\section{Conclusions}

$\nabla$

Twelve-month qualitative results from this study, in which subjects will be followed for 5 years, indicate similar efficacy, quality of life, and safety for both treatment groups.

\section{Acknowledgements}

The authors wish to thank Wainwright Medical Communications (Los Gatos, California USA) for assistance with research and editorial support. The authors also thank Innovative Analytics (Kalamazoo, Michigan USA) for statistical analysis of the study data.

\section{Conflict of Interest}

\section{$\nabla$}

Halt Medical, Inc. (Brentwood, California USA) sponsored the study and provided materials and funding for the described procedures and for independent third-party monitoring, statistical analyses, and writing support. None of the authors have other commercial disclosures.

\section{References}

1 Zimmermann A, Bernuit D, Gerlinger C, Schaefers M, Geppert K. Prevalence, symptoms and management of uterine fibroids: an international internet-based survey of 21,746 women. BMC Women's Health 2012; 12: 6; Online: http://www.biomedcentral.com/1472-6874/12/6; last access: 07.10.2014

2 Taran FA, Tempany CM, Regan L et al.; for the MRgFUS Group. Magnetic resonance-guided focused ultrasound (MRgFUS) compared with abdominal hysterectomy for the treatment of uterine leiomyomas. Ultrasound Obstet Gynecol 2009; 34: 572-578

3 Twijnstra AR, Kolkman W, Trimbos-Kemper GC et al. Implementation of advanced laparoscopic surgery in gynecology: national overview of trends. J Minim Invasive Gynecol 2010; 17: 487-492

4 Munro MG. Uterine leiomyomas, current concepts: pathogenesis, impact on reproductive health, and medical, procedural, and surgical management. Obstet Gynecol Clin North Am 2011; 38: 703-731

5 Pritts EA, Parker $W H$, Olive DL. Fibroids and infertility: an updated systematic review of the evidence. Fertil Steril 2009; 91: 1215-1223

6 Shokeir T, El-Shafei M, Yousef H et al. Submucous myomas and their implications in the pregnancy rates of patients with otherwise unexplained primary infertility undergoing hysteroscopic myomectomy: a randomized matched control study. Fertil Steril 2010; 94: 724-729

7 Holzer A, Jirecek ST, Illievich UM et al. Laparoscopic versus open myomectomy: a double-blind study to evaluate postoperative pain. Anesth Analg 2006; 102: 1480-1484

8 Chudnoff SG, Berman JM, Levine DJ et al. Outpatient procedure for the treatment and relief of symptomatic fibroids. Obstet Gynecol 2013; 121: 1075-1082

9 Guido RS, Macer JA, Abbott K, Falls JL, Tilley IB, Chudnoff SG. Radiofrequency volumetric thermal ablation of fibroids: a prospective, clinical analysis of two years' outcome from the Halt trial. Health Qual Life Outcomes 2013; 11: 139; Online: http://www.hqlo.com/content/11/1/ 139; last access: 07.10.2014

10 Berman JM, Guido RS, Garza Leal JG et al. Three years' outcome from the Halt trial: a prospective analysis of radiofrequency volumetric thermal ablation of myomas. J Minim Invasive Gynecol 2014; 21: 767-774

11 Brucker SY, Hahn M, Kraemer D et al. Laparoscopic radiofrequency volumetric thermal ablation of fibroids versus laparoscopic myomectomy. Int J Gynaecol Obstet 2014; 125: 261-265

12 Spies JB, Coyne K, Guaou Guaou N et al. The UFS-QOL, a new diseasespecific symptom and health-related quality of life questionnaire for leiomyomata. Obstet Gynecol 2002; 99: 290-300

13 Coyne KS, Margolis MK, Bradley LD et al. Further validation of the uterine fibroid symptom and quality-of-life questionnaire. Value Health 2012; 15: 135-142

14 Agency for Healthcare Research and Quality, Rockville, MD. U.S. Valuation of the EuroQol EQ-5D Health States. December 2005. Online: http://www.ahrq.gov/rice/EQ5Dproj.htm; last access: 07.10.2014

15 Bushnell DM, Martin ML, Moore KA et al. Menorrhagia Impact Questionnaire: assessing the influence of heavy menstrual bleeding on quality of life. CMRO 2010; 26: 2745-2755

16 Galen DI, Isaacson $K B$, Lee $B B$. Does menstrual bleeding decrease after ablation of intramural myomas? A retrospective study. J Minim Invasive Gynecol 2013; 20: 830-835

17 Baird DD, Garrett TA, Laughlin SK et al. Short-term change in growth of uterine leiomyoma: tumor growth spurts. Fertil Steril 2011; 95: 242246 